\title{
FREE VIBRATION ANALYSIS OF HYPERBOLIC COOLING TOWER
}

\author{
Shivanand Mendigeri \\ P.G Student, Dept. of Civil Engineering \\ KLS, Gogte Institute of Technology, Belagavi
}

\begin{abstract}
The present paper discusses on free vibration analysis of hyperbolic cooling tower. An attempt has been made in this paper to study the influence of shell thickness on free vibration. FEA based ANSYS software is utilized to model the tower shell using 4 node SHELL 181 element and 2 node 188 BEAM element to model column support considering fixed boundary condition and column supported shell. The mesh size is adopted after convergence study. The tower has 88 columns, each with the length of $L_{c}$ $=12.5 \mathrm{~m}$ and cross section of $0.61 \mathrm{~m} \times 1.32 \mathrm{~m}$ in the radial and circumferential directions, respectively. Material properties adopted are Elastic modulus $\mathbf{E}=\mathbf{2 7 G P a}$, Poisson's ratio $\mu=0.167$ and Reinforced concrete with a unit weight $\rho=24 \mathrm{kN} / \mathrm{m}^{3}$. The natural frequencies for first seven modes are studied for fixed and column supported cooling tower and difference between the fixed and column supported cooling tower are observed. The difference in frequencies between fixed base and column supported shell are observed to be $6 \%$ to $12 \%$ for first 7 modes.
\end{abstract}

Keywords - cooling tower, shell, frequencies, free vibration

\section{INTRODUCTION}

Reinforced concrete cooling towers are huge thin shell structures which are the essential components of the thermal and nuclear power stations. They may be subjected to a variety of loading conditions such as self-weight, wind load, earthquake load, temperature and construction loads. The loads applied by a design earthquake to the shell and components of a cooling tower can be determined by the response spectrum method which is one of the most appropriate technique requiring a free vibration analysis to evaluate the natural frequencies. In other words, the magnitude of the earthquake-induced forces is a function of the dynamic properties of the structures such as natural frequency. Therefore, free vibration characteristics of such cooling tower structures are crucial in the design process.

\section{LITERATURE SURVEY}

Considerable research is available in the literature related to free vibration study. Stoneking J. E (1973) Performed free vibrations on shells of revolution with variable thickness. They calculated the natural frequencies and mode shapes of

\author{
Sachin Kulkarni \\ Assistant Professor, Dept. of Civil Engineering \\ KLS, Gogte Institute of Technology, Belagavi
}

shells of revolution with variable thickness. Results indicated that moderate variations in shell thickness do not appreciably affect the natural frequencies, but may significantly affect mode shapes. Debnath J. M (1974) Performed free vibration, stability and "non-classical modes" of cooling tower shells. The two elements were used to analyze a hyperboloid tower shell. The effects introduced by the legs of the cooling tower are studied by omitting parts of the shell near the base. They concluded that "non-classical" modes of vibration exist when the shell is completely rotationally symmetric without any singularities and natural frequencies are lower than for the complete shell, and those there in "non-classical" modes of vibration. Nelson and Thomas (1978) Performed free vibration analysis of cooling towers with column supports using finite element method. They studied the behavior of cooling tower using finite element method and compared with experimental values. They concluded that the finite element method described accurately predicts the resonant behavior of cooling towers with column supports. The agreement between theoretical and experimental values of resonant frequency is better than $5 \%$. Winney P. E (1978) Studied modal properties of cooling tower. Resonance tests have been carried out on a model and full scale cooling tower to determine the resonant frequencies and mode shapes. A comparison between values of damping ratio for model and full scale are made, and the agreement is very good with the exception of mode 4 which shows a $30 \%$ error. Calladine C. R (1982) Studied natural frequencies of cooling tower shells. He studied fundamental natural frequency of vibration of a uniform hyperboloid cooling tower shell mounted on a rigid base, and the circumferential wavenumber associated with fundamental mode and suggest the formulae. By comparing the results he concluded that the above suggested formulae is satisfactory as first approximation, giving fundamental frequencies not more than about $10 \%$ low and corresponding circumferential wave numbers low by about 0.5. Nelson R.L (1981) Performed finite element for analyzing accurately the free vibrations of cooling towers. They studied the effect of changing the dimensions of ring beam and column supports. They concluded that the resonant frequencies of a tower rapidly decrease if the foundation rigidity decreases beyond a given value. They also found that the effect of Poisson's ratio was negligible. Nasir A.M. et al. (2002) found that the influence of height was seen to have greatest influence on the free 
vibration response of cooling tower. As an increase of height significantly increased the period of vibration. And increase in the curvature causes the fundamental modal periods to decrease first; at large curvature this trend was reversed. They also observed that the period of the first lateral mode is unaffected by a change in the thickness but it occurs earliest in the thickest shell.

\section{FREE VIBRATION ANALYSIS}

The free vibration analysis in structural system is to determine the natural mode shapes and frequencies of the structure during vibration. The types of equation which arise from modal analysis are those seen in Eigen systems. Sometimes, the only desired modes are the lowest frequencies because they can be the most prominent modes at which the object will vibrate, dominating all the higher frequency modes.

\section{OBJECTIVE OF THE STUDY}

1] To study the free vibration response of fixed base cooling tower shell for varying shell thickness.

2] To study the free vibration response of column supported cooling tower shell for varying shell thickness.

3] To study the comparison on different column configuration arrangement.

4] To study the difference in frequencies of fixed base shell and column supported shell.

\section{PROBLEM STATEMENT}

Numerical example considered for free vibration analysis is from reference Yang T.Y et.al (1983) ${ }^{13}$. The cooling tower considered is defined by the following parameters: radius at the base of the shell $R_{b}=55.58 \mathrm{~m}$; radius at the throat $R_{t}=$ $35.5 \mathrm{~m}$; radius at the top $\mathrm{R}_{\mathrm{T}}=37.49 \mathrm{~m}$; height of the shell excluding the columns $\mathrm{h}=137.08 \mathrm{~m}$; height from the throat to the top of the shell $\mathrm{h}_{2}=30.14 \mathrm{~m}$; and modulus of elasticity $\mathrm{E}=$ $27590 \mathrm{~N} / \mathrm{mm}^{2}$; Poisson's ratio $\mu=0.167$; mass density $\rho=24$ $\mathrm{kN} / \mathrm{m}^{3}$. The tower has 88 columns, each with the length of $\mathrm{L}_{\mathrm{c}}=$ $12.5 \mathrm{~m}$ and cross section of $0.61 \mathrm{~m} \times 1.32 \mathrm{~m}$ in the radial and circumferential directions, respectively.

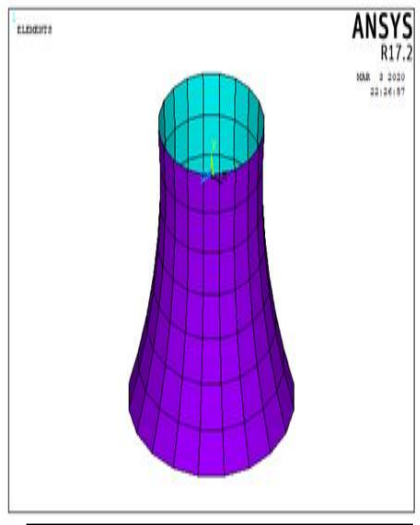

Fig 1 Fixed base model

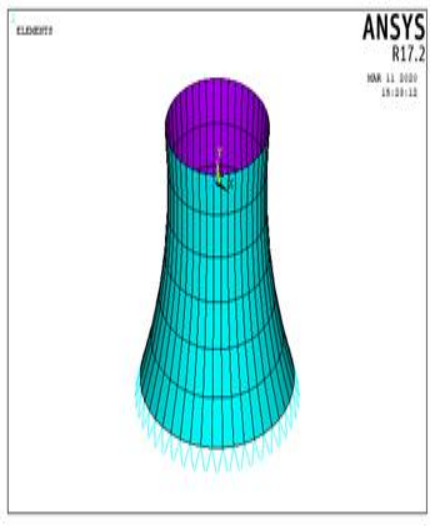

Fig 2 Column supported model
1] Free vibration analysis of fixed base cooling tower shell The above example is considered for the analysis of cooling tower shell with fixed base to study the Natural Frequency of First 7 Modes for varying shell thickness $(180 \mathrm{~mm}, 210 \mathrm{~mm}$, 240mm, 270mm and $300 \mathrm{~mm}$ ).

Table 1 Natural Frequency for first 7 modes for varying SHELL thickness for fixed base cooling tower

\begin{tabular}{|c|c|c|c|c|c|}
\hline & \multicolumn{5}{|c|}{ Shell Thickness (mm) } \\
\hline $\begin{array}{c}\text { Mode } \\
\text { number }\end{array}$ & 180 & 210 & 240 & 270 & 300 \\
\hline & \multicolumn{5}{|c|}{ Natural Frequency (Hz) } \\
\hline 1 & 1.034 & 1.0902 & 1.1179 & 1.1391 & 1.1472 \\
\hline 2 & 1.034 & 1.0908 & 1.1184 & 1.1391 & 1.1472 \\
\hline 3 & 1.0656 & 1.1049 & 1.1317 & 1.1489 & 1.1814 \\
\hline 4 & 1.0663 & 1.1049 & 1.1317 & 1.1489 & 1.1819 \\
\hline 5 & 1.1194 & 1.1252 & 1.1812 & 1.2616 & 1.3206 \\
\hline 6 & 1.1194 & 1.1252 & 1.1812 & 1.2616 & 1.3207 \\
\hline 7 & 1.2194 & 1.2407 & 1.2648 & 1.2915 & 1.3454 \\
\hline
\end{tabular}

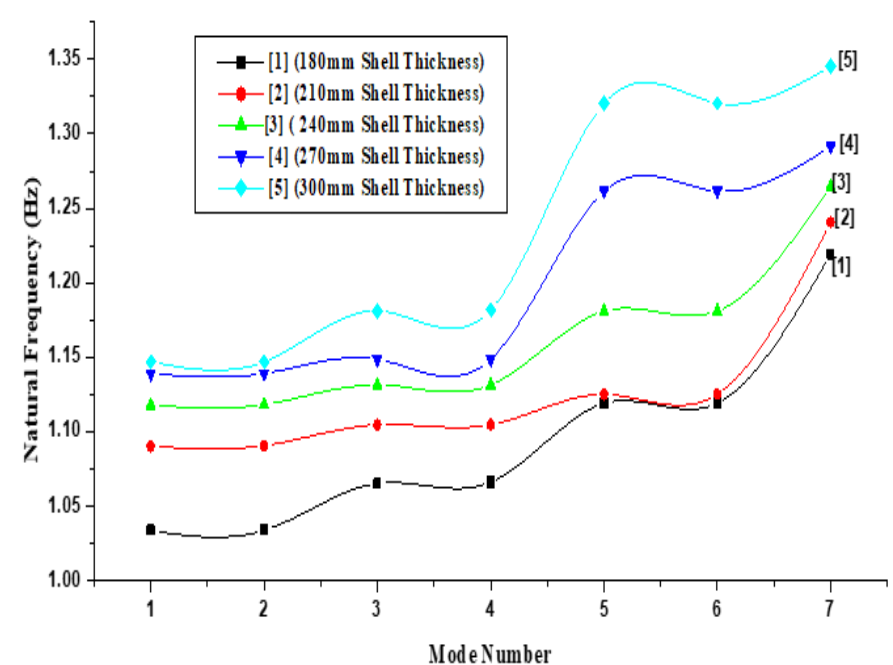

Figure 3 Natural frequencies v/s Mode number for fixed base cooling tower shell

It is observed from the analysis of fixed base shell that natural frequencies increase upon increase in shell thickness. The natural frequency remains almost same for first few modes as depicted in figure 3. As shell thickness is increased the mass contribute maximum and excites, thus increase in frequencies and time period reduces. Since the base of shell is made fixed, the influence of shell thickness is prominent.

2] Free vibration analysis of column supported cooling tower shell

The Natural Frequency of First 7 Modes for varying shell thickness $(180 \mathrm{~mm}, 210 \mathrm{~mm}, 240 \mathrm{~mm}, 270 \mathrm{~mm}$ and $300 \mathrm{~mm})$ are listed in table 2 . 
Table 2 Natural Frequency for first 7 modes for varying SHELL thickness for column supported shell

\begin{tabular}{|c|c|c|c|c|c|}
\hline \multirow{3}{*}{$\begin{array}{c}\text { Mode } \\
\text { number }\end{array}$} & 180 & 210 & 240 & 270 & 300 \\
\cline { 2 - 6 } & \multicolumn{5}{|c|}{ Natural Frequency (Hz) } \\
\cline { 2 - 6 } & \multicolumn{5}{|c|}{ Shell Thickness (mm) } \\
\hline 1 & 0.9767 & 1.0011 & 1.0125 & 1.0265 & 1.0429 \\
\hline 2 & 0.97674 & 1.0012 & 1.0126 & 1.0266 & 1.043 \\
\hline 3 & 0.99248 & 1.0286 & 1.0694 & 1.1102 & 1.1502 \\
\hline 4 & 0.99256 & 1.0287 & 1.0695 & 1.1103 & 1.1503 \\
\hline 5 & 1.0648 & 1.0728 & 1.0855 & 1.1456 & 1.2027 \\
\hline 6 & 1.065 & 1.0729 & 1.0855 & 1.1456 & 1.2028 \\
\hline 7 & 1.0746 & 1.0995 & 1.1391 & 1.1829 & 1.2072 \\
\hline
\end{tabular}

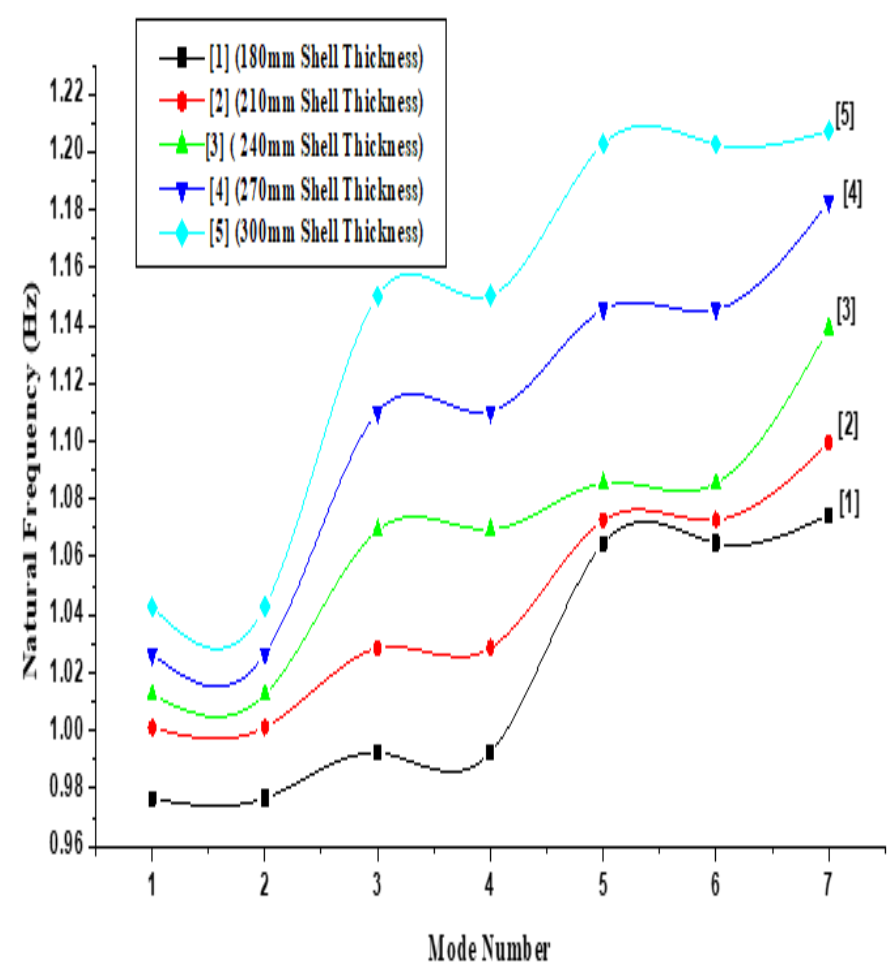

Figure 4 Natural frequencies v/s Mode number for column supported shell

The column supported shell shows least frequency values as compared to fixed base shell. As column provides weak link to the shell. Thus the flexibility of the structure increases, thus reduction in excitation of mass and produce low frequencies. The natural frequency remains almost same for first few modes as depicted in figure 4.
Table 3 Natural Frequency for first 7 modes for Different column configurations (Rectangular and circular).

\begin{tabular}{|c|c|c|c|}
\hline \multirow{3}{*}{$\begin{array}{c}\text { Mode } \\
\text { Number }\end{array}$} & Rectangular & Circular & \multirow{2}{*}{ Percentage } \\
\cline { 2 - 3 } & \multicolumn{2}{|c|}{ Natural Frequency (Hz) } & \\
\cline { 2 - 3 } & $\mathbf{6 1 0 \mathrm { mm } \times 1 3 2 0 \mathrm { mm } )}$ & $(1012.5 \mathrm{~mm}$ Dia. & \\
\hline 1 & 1.0429 & 1.1414 & 8.62 \\
\hline 2 & 1.043 & 1.1414 & 8.62 \\
\hline 3 & 1.0659 & 1.147 & 7.1 \\
\hline 4 & 1.066 & 1.147 & 7.1 \\
\hline 5 & 1.2027 & 1.2575 & 4.36 \\
\hline 6 & 1.2028 & 1.2575 & 4.34 \\
\hline 7 & 1.2072 & 1.2875 & 6.24 \\
\hline
\end{tabular}

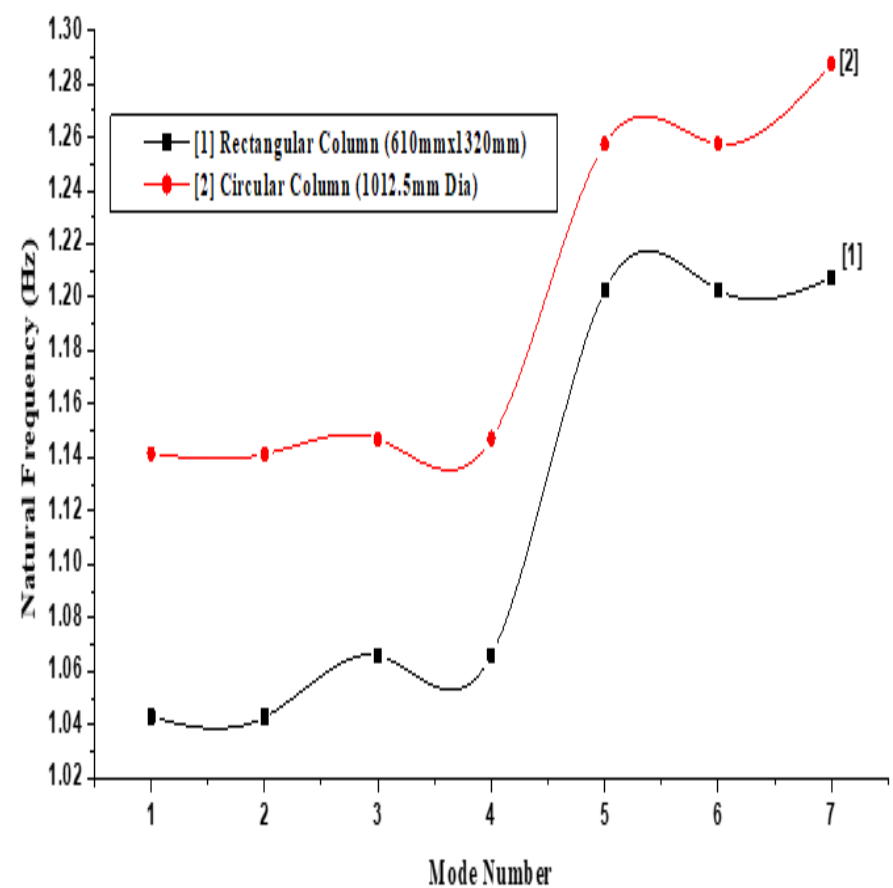

Figure 5 Natural frequencies v/s Mode number for Different column configuration of column supported shell

The comparison of different column configurations is made by changing the cross sections of column. Rectangular and circular cross sections are adopted for study and compared. The effect of cross section of column on free vibration response is observed and tabulated in table 3. The circular cross section of column gave rise to higher frequency values as compared to rectangular. Because the circular cross section is stronger and stiffer than rectangular cross section. 
3] Difference in Natural frequencies for fixed base and column supported cooling tower shell.

The difference in natural frequencies for fixed base and column supported cooling tower shell is studied for first seven modes.

Table 4 Difference in natural frequencies for fixed base and column supported cooling tower shell

\begin{tabular}{|c|c|c|c|}
\hline \multirow{2}{*}{$\begin{array}{c}\text { Mode } \\
\text { number }\end{array}$} & $\begin{array}{c}\text { Fixed base } \\
\text { shell }\end{array}$ & $\begin{array}{c}\text { column } \\
\text { supported }\end{array}$ & \multirow{2}{*}{$\begin{array}{c}\text { Percentage } \\
\text { Difference }\end{array}$} \\
\cline { 2 - 3 } & \multicolumn{2}{|c|}{ Natural Frequency (Hz) } & \\
\hline 1 & 1.034 & 0.9767 & 5.54 \\
\hline 2 & 1.034 & 0.97674 & 5.54 \\
\hline 3 & 1.0656 & $\mathbf{0 . 9 9 2 4 8}$ & 6.86 \\
\hline 4 & 1.0663 & 0.99256 & 6.9 \\
\hline 5 & 1.1194 & 1.0648 & 4.9 \\
\hline 6 & 1.1194 & 1.065 & 4.9 \\
\hline 7 & 1.2194 & 1.0746 & 11.87 \\
\hline
\end{tabular}

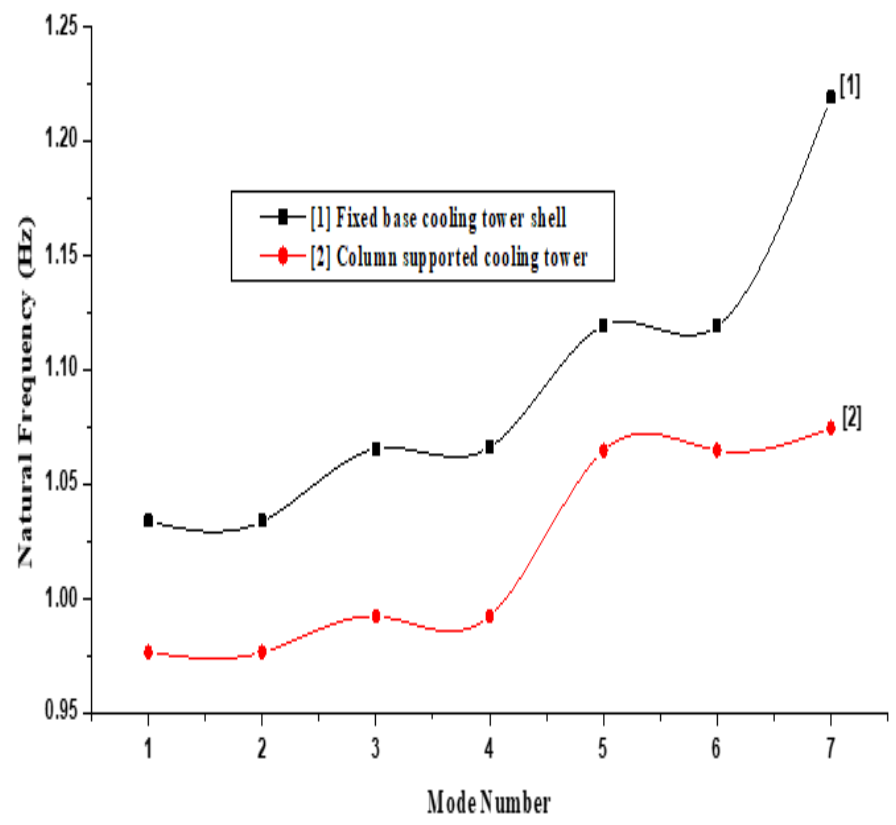

Figure 6 Natural frequencies v/s Mode number for Different column configuration of column supported shell

The difference in natural frequencies for fixed base shell and column supported cooling tower shell is depicted in table 4. It is observed that natural frequency reduces for column supported shell as compared to fixed base shell. Columns provide the weakest link to the tower shell, thus increase in flexibility. The difference in frequencies between fixed base and column supported shell are observed to be $6 \%$ to $12 \%$ for first 7 modes.

\section{CONCLUSION}

An attempt has been made to study the influence of shell thickness on free vibration analysis. Two boundary conditions [fixed base and column support] are studied and first seven modes of vibration are observed. The natural frequencies and mode shapes are studied. Further different column configurations are compared and difference in natural frequencies for fixed base and column supported shell are tabulated. Following conclusions could be drawn from the analysis.

1] The natural frequencies increases as shell thickness is increased for fixed base shell, whereas in the column supported shell the frequencies reduces as compared to fixed base. Because of increase in flexibility due to provision of columns.

2] The study on different column configurations [rectangular and circular cross section] revealed that, the circular cross section leads to higher frequency values as compared to rectangular cross section because of high stiffer and stronger in cross section.

3] The percentage difference in natural frequency for fixed base and column supported shell are tabulated. The difference in frequencies between fixed base and column supported shell are observed to be $6 \%$ to $12 \%$ for first 7 modes.

\section{REFERENCES}

[1] Stoneking J. E (1973) "Free vibrations of shells of revolution with variable thickness" nuclear engineering and design, Vol.24, pp.314-321.

[2] Phillip L. G, Suber K. S and Herman S (1974) "Dynamic analysis of column-supported hyperboloidal shells" earthquake engineering and structural dynamics, Vol.2, pp.269-279.

[3] Debnath J. M (1974) "free vibration, stability and nonclassical modes of cooling tower shells" Journal of Sound and Vibration, Vol.33, pp.79-101.

[4] Nelson R. L And Thomas D.L (1978) "Free vibration analysis of cooling towers with column supports", Journal of Sound and Vibration, Vol. 57, pp.149-153.

[5] Carl S. G and Yang T Y (1978) "Nastran and sap iv applications on the seismic response of column-supported cooling towers" Computers and Structures. Vol 8, pp. 161168. 


\section{International Journal of Engineering Applied Sciences and Technology, 2020 \\ Vol. 5, Issue 1, ISSN No. 2455-2143, Pages 285-289 \\ Published Online May 2020 in IJEAST (http://www.ijeast.com)}

[6] Winney P. E (1978) "The modal properties of model and full scale cooling towers" Journal of Sound and Vibration, Vol.57, pp.131-148.

[7] Calladine C. R (1982) "Natural frequencies of cooling tower shells" Journal of Sound and Vibration. Vol.82, pp.345-362.

[8] Emilia J and Zdenek B (1983) "Vibration characteristics of a cooling-tower shell" Journal of Wind Engineering and Industrial Aerodynamics, Vol. 12, pp.145-154.

[9] Aksu T (1996) “A finite element formulation for columnsupported hyperboloid cooling towers" Computers and structures, Vol. 59, pp. 965-914.

[10] Tan D. Y (1998) "Free vibrational analysis of shells of revolution", Journal of Sound and Vibration, Vol.213, pp.1533.

[11] Nasir A.M ,Thambiratnam D. P, Butler D., Austin P. (2002) "Dynamics of axisymmetric hyperbolic shell structures" Thin-Walled Structures, Vol.40, pp.665-690.

[12] Horr A.M and Safi M (2002) "Full Dynamic Analysis of Large Concrete Cooling Towers: Soil-Structure Interaction" International Journal of Space Structures Vol. 17, pp.301-312.

[13] Yang T and Kapania R (1983) "Shell elements for cooling tower analysis" Journal of engineering mechanics, ASCE, Vol. 109, pp.1270-1289.

[14] Basu P. and Gould P. (1979) "Finite Element Discretization of open-type Axisymmetric elements" International Journal for numerical methods in engineering, Vol.14, pp.159-178.

[15] Bhimaraddi A., Peter J. and Athol J. (1991) "Freevibration response of column-supported, ring-stiffened cooling tower" Journal of engineering mechanics, ASCE, Vol. 117, pp.770-788.

[16] Chowdhury A. and Kostem C. (1991) "Significance of mesh-fineness in accuracy of finite element analysis of hyperbolic cooling tower shells", Computers\& Structures, Vol. 40. pp. 237-241.

[17] Chauvel D. and Costaz J. (1991) "Studies of column supported towers" Journal of Structural Engineering, ASCE Vol.13, pp.310-316.
[18] Caol M. and Xing Q. (2014) "Stress and Stability Analysis of A Cooling Tower by ANSYS" Advanced Materials Research, Vols. 919, pp. 222-225.

[19] Karisiddappa N., Viladkar N., Godbole and Prem K. (1998) "Finite element analysis of column supported hyperbolic cooling towers using semi-loof shell and beam elements" Engineering Structures, Vol. 20, pp. 75-85.

[20] Kanga J. and Arthur W. (2005) "Three-dimensional vibration analysis of thick hyperboloidal shells of revolution" Journal of Sound and Vibration, Vol.282, pp.277-296.

[21] Meschke G., Herbert A. and Peter K. (1991) "Finite element analyses of cracked cooling tower shell" Journal of Structural Engineering, ASCE Vol.117, pp.2620-2638.

[22] Nelson L. (1981) "Analyses of cooling tower dynamics" Journal of Sound and Vibration, Vol.79, pp.501-518.

[23] Nandini M. and Guruprasad N. (2017) "Study on influence of inverted $\mathrm{v}$ and $\mathrm{w}$-frame column support on dynamic behavior of hyperbolic cooling tower under seismic loading" International Research Journal of Engineering and Technology, Vol.07, pp.2860-2865.

[24] Sabouri G. and Kharrazi M. (2005) "Reinforced Concrete Column Supported Hyperboloid Cooling Tower Stability Assessment for Seismic Loads" Scientia Iranica, Vol.12, pp.241-246.

[25] Wolf J. and Skrikerud P. (1980) "Influence of geometry and of the constitutive law of the supporting columns on the seismic response of a hyperbolic cooling tower "Earthquake engineering and structural dynamics, Vol. 8, pp.415-437.

[26] Wang S. and Wenda L. (1990) "Theoretical and experimental solutions of cooling-tower- soil system" Journal of engineering mechanics, ASCE, Vol. 116, pp.862-869.

[27] Yong Y. and Lin Y. (1985) "Free and random vibrations of column-supported cooling towers" Journal of Sound and Vibration, Vol.98, pp.539-563. 